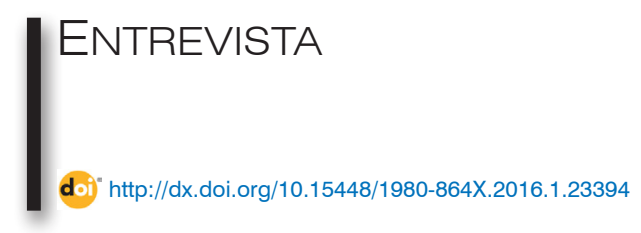

\title{
Camisas Verdes, 45 anos depois - uma entrevista com Hélgio Trindade
}

\author{
Green Shirts, 45 years later \\ - an interview with Hélgio Trindade \\ Camisas Verdes, 45 años después \\ - una entrevista con Hélgio Trindade
}

\author{
René E. Gertz* \\ Leandro Pereira Gonçalves** \\ Vinícius Liebel*** \\ (Entrevistadores)
}

Na historiografia brasileira, conta-se nos dedos das mãos os autores que atingem o status de referência unânime em determinado tema. Ainda mais raro é que essa referência venha de outras áreas. Formado em Ciências Jurídicas e Sociais e com um doutorado em Ciência Política, Hélgio Trindade é uma dessas raras exceções. Não há estudo sobre o integralismo que não tenha, de alguma forma, dialogado com seu Integralismo: o Fascismo Brasileiro da década de 30. E isso já acontece há quarenta e cinco anos.

A relevância do professor Hélgio Trindade no meio acadêmico brasileiro, entretanto, não se resume a esse estudo pioneiro. Tanto na docência quanto na pesquisa e na administração universitária, o caminho por ele trilhado é marcado pela excelência e pelo reconhecimento. Sua

* Professor Titular do PPG-História da Pontifícia Universidade Católica do Rio Grande do Sul (PUCRS).<gertz@pucrs.br>

** Professor adjunto do PPG-História da Pontifícia Universidade Católica do Rio Grande do Sul (PUCRS).<leandro.goncalves@pucrs.br>

*** Professor Colaborador do PPG-História da Pontifícia Universidade Católica do Rio Grande do Sul (PUCRS) e bolsista Capes/PNPD na mesma instituição. <v.liebel@uol.com.br> 
atuação docente se desenvolveu em instituições reconhecida qualidade, a começar pela Universidade Federal do Rio Grande do Sul (UFRGS) - da qual é professor emérito -, como também na PUCRS e nas várias instituições onde atuou como professor visitante, como o Institut des Hautes Études de l'Amérique Latine e a Stanford University. Em sua carreira de pesquisador passou por inúmeros centros e institutos de pesquisa, como o IDESP (Instituto de Estudos Econômicos, Sociais e Políticos de São Paulo), o CERI (Centre d'Études et de Recherches Internationales) e a École des Hautes Études en Sciences Sociales de Paris. Exerceu ainda a função de reitor não apenas na Universidade Federal do Rio Grande do Sul (UFRGS), mas também na Universidade Federal da Integração Latino-Americana (UNILA), na qual tomou parte em um projeto ambicioso e pioneiro pela integração continental. Partindo do intercâmbio acadêmico e da formação de indivíduos cultural e socialmente conscientes da diversidade latino-americana, a instituição tem como vocação a aproximação dos países do continente e de seus povos. Trindade esteve à frente desse importante projeto desde seus primórdios.

Nas páginas que se seguem, é natural que os camisas verdes, os integralistas, ocupem a ampla maioria do espaço. O aniversário de 45 anos da tese do professor Hélgio Trindade e o anúncio do lançamento de seu mais recente livro, também com a temática do integralismo (A Tentação Fascista no Brasil: imaginário de dirigentes e militantes integralistas) deixam, compreensivelmente, sua marca manifesta nas questões e nas respostas do entrevistado. Mas isso é também o que faz desta entrevista um evento marcante para a historiografia brasileira. Ter a oportunidade de ouvir (e ler) um pesquisador do calibre do professor Hélgio Trindade falando de sua própria obra e sobre o estado da arte das pesquisas acerca do integralismo é um raro privilégio, assim como é um privilégio para a revista Estudos Ibero-Americanos poder publicar esta entrevista. Não poderia haver um fecho melhor para um dossiê acerca dos Pensamentos e Práticas Politicas Conservadoras no Século XX.

Boa leitura! 
- Prof. Hélgio Trindade, a motivação principal - ainda que não exclusiva - desta nossa entrevista é o fato de que sua tese $L^{\prime}$ Action intégraliste brésilienne: un mouvement de type fasciste au Brasil, defendida na França, mais tarde publicada sob o título Integralismo: o fascismo brasileiro na década de 30 está completando 45 anos. O senhor poderia fazer um - ainda que breve - relato do contexto pessoal, acadêmico brasileiro e francês, e político nacional em que ela foi produzida?

- A pergunta é complexa para ser sintetizada numa resposta. Tentei explicitar melhor esse contexto no meu ultimo livro - A Tentação Fascista no Brasil: imaginário de dirigentes e militantes integralistas a ser publicado no primeiro semestre de 2016 . O contexto pessoal mais amplo decorre de minha intensa participação na política estudantil antes do golpe de 64 na luta pela Reforma e o Co-Governo Universitário. Como muitos jovens da minha geração experimentei a violência das restrições à liberdade, imposta pelos militares no poder e decidi sair do Brasil no segundo ano da ditadura militar brasileira, em busca de novos espaços intelectuais, visando construir uma futura carreira universitária na área da ciência política.

$\mathrm{Na}$ França, vários fatores estimularam-me a escolher a Ação Integralista Brasileira (AIB) como tema de minha tese de doutorado. De um lado, porque no Brasil ela era, até então, um tema marginal, e poderia dizer estigmatizado, nos campos da história e das ciências sociais. De outro, na Europa havia uma grande florescência na produção acadêmica sobre o nazi-fascismo, incluindo a valorização desses estudos na França, onde algumas interpretações atribuíam as raízes intelectuais do fascismo às últimas décadas do século XIX francês.

Na época, pesquisas e livros sobre populismo, autoritarismo, ditadura e fascismo começavam a adquirir importância na produção intelectual internacional e latino-americana. No Brasil, muitos historiadores, sociólogos e jornalistas políticos se lançaram em pesquisas e análises sobre a Revolução de 1930, expandindo-as para o "Ciclo Vargas". Alguns "brasilianistas" se dedicaram a pesquisas sobre o positivismo castilhista, as elites regionais da Primeira República e também o Estado Novo de Vargas no contexto internacional de hegemonia do nazi-fascismo. $\mathrm{Na}$ Argentina, o peronismo foi foco de interesse de sociólogos e classificado como "fascismo de esquerda". Noutra perspectiva, começam a ser publicados os primeiros estudos sobre os "ensaístas autoritários", como precursores do pensamento brasileiro no período entre as duas guerras mundiais. 
Em Paris, no Institut d'Études Politiques da FNSP, onde fiz minha tese, participei do seminário de doutorado, dirigido pelo meu futuro orientador, Jean Touchard, cujo tema proposto foi uma pesquisa comparada da "década de 1930", para os alunos de diferentes países. Esse desafio levou-me a pensar sobre esse processo no Brasil, neste período, e suas possíveis influências dos regimes e movimentos nazifascistas europeus em ascensão. Nesse ambiente intelectual lanceime num estudo comparativo sobre esse período crítico na Europa, especialmente a partir da matriz do fascismo e do nacional-socialismo. Houve também a coincidência que na pequena biblioteca da Maison du Brésil, onde eu residia, encontrei a coleção das Obras Completas de Plínio Salgado, ex-Chefe Nacional da AIB. Todos esses fatores foram favoráveis ao meu engajamento nessa problemática comparativa, instigado também pelo "ceticismo" inicial do meu orientador, com relação à possibilidade do Integralismo ser um movimento de tipo fascista extra-europeu. Enfrentei igualmente o desafio de uma imersão na literatura internacional e nas fontes brasileiras, através da literatura, documentos recuperados e entrevistas com ex-dirigentes nacionais, regionais e locais para desenvolver meu argumento e as bases empíricas da demonstração da tese.

- Como a tese de Carlos Henrique Hunsche sobre o integralismo brasileiro, defendida na Alemanha ainda nos anos 1930, era totalmente desconhecida no Brasil, seu trabalho foi pioneiro. Interessante é que, simultaneamente, estavam em andamento trabalhos paralelos ao seu (Robert Levine, Hélio Silva, Elmer Broxson). O Senhor tem alguma explicação para esse interesse pelo tema, naquele momento?

- Na resposta anterior referi-me justamente as esses autores citados - os brasilianistas - e muitos outros. A diferença é que, atualmente, as agendas de pesquisa são articuladas através de redes interinstitucionais com as novas ferramentas da informática. $\mathrm{Na}$ época, não havia essa possibilidade. Pesquisadores individuais ou em grupo, vinculados a universidades brasileiras ou internacionais, começaram a valorizar esse período em suas pesquisas e publicações na Europa, Estados Unidos e na América Latina. Muitos dos autores de obras clássicas sobre o nazi-fascismo haviam emigrado da Alemanha de Hitler, em direção à Inglaterra e, sobretudo, aos Estados Unidos. É interessante reconstituir essas redes interpessoais, com publicações de coletâneas reunindo autores de obras fundadoras. Essas fontes disponíveis foram 
muito importantes para a minha pesquisa, incluindo a produção italiana, francesa, espanhola mais centrada no fascismo.

$\mathrm{Na}$ América Latina, o tema do fascismo retornou num intenso debate, no exílio mexicano, sobre as novas formas de "fascismo" aplicáveis às ditaduras militares, tendo como caso paradigmático o Chile de Pinochet. Novas variantes do fascismo foram elaboradas ("fascismo dependente" ou "fascismo sui generis") para caracterizar esses regimes. As interpretações foram se radicalizando, mas não vingaram pela inconsistência da transposição de categorias conceituais em face da distância do contexto histórico europeu de ascensão dos fascismos clássicos.

No Brasil, a historiografia dominante estava centrada na história econômica, sem valorizar a historia política do período. A partir de meados da década de 1960, iniciam-se as primeiras pesquisas focadas na Primeira Republica e na ruptura da Revolução de 30 com a política oligárquica. A convergência entre os estudos latino-americanos sobre o esgotamento do Estado oligárquico e a emergência dos populismos na Argentina, Brasil e México deslocou o eixo da agenda de pesquisa para questões ainda não suficientemente exploradas pela historiografia tradicional. Foi nesse contexto acadêmico e político que minha tese sobre o Integralismo encontrou as bases da sua construção.

Sobre a tese de filosofia de Hunsche, defendida na Universidade de Berlim e publicada em 1930, reconheço que foi pioneira, mas desconhecida no Brasil e na própria Alemanha. Na época em que ele a escreveu foi obviamente influenciado pelo contexto político-ideológico de plena ascensão do nazismo. Consegui descobri-la através de uma nota de pé de página no livro de Thomas Skidmore (Brasil: De Getulio à Castelo). Tentei localizá-la e pedi a um colega que estudava na Alemanha que me auxiliasse. Ele, através do sistema de bibliotecas descobriu um único exemplar na pequena Biblioteca Municipal de Mannheim. Foi como tive acesso a uma copia do livro raríssimo. Quando, durante Governo Geisel, ele teve autorização para retornar ao Brasil, - já que havia sido considerado colaborador com regime nazista como locutor para o Brasil da rádio de Berlim - fui visitá-lo em Gramado onde possuía uma pequena pousada. $\mathrm{Na}$ ocasião, explicou-me que a raridade de seu livro devia-se à apreensão pela Gestapo da maioria dos exemplares, sem que justificasse claramente as razões da mesma.

Seu trabalho teve o mérito de analisar a AIB em relação à ideologia do fascismo italiano e do nacional-socialismo. Incorporou, também, movimentos de outros países do sul da Europa que eram proto-fascistas, 
monarco-corporativistas ou conservadores católicos. Seu foco foi mostrar que, apesar dessas influências (especialmente portuguesas), a diferença principal do integralismo com relação ao nazismo era que este defendia a concepção da raça pura ariana e aquele valorizava a mistura étnica (melting pot). Como seu enfoque era filosófico, limitou-se a apresentar a ideologia Integralista numa perspectiva doutrinária, buscando demonstrar que fora fruto de influências de movimentos europeus, dentre os quais destacava-se o Integralismo Lusitano de Sardinha.

- A publicação da tese no Brasil ocorreu em 1974, quais as principais reações de setores da opinião pública, de que o Senhor se recorda? Por acaso, sofreu alguma crítica mais agressiva, considerando o contexto político da época? $\mathrm{Ou}$, pelo contrário, as críticas foram benignas?

- Quando defendi minha tese, no inicio de 1972, sobre um tema do passado pouco valorizado na literatura acadêmica, comecei a imaginar as dificuldades a serem enfrentadas se quisesse publicá-la no Brasil. Estávamos em plena ditadura militar e o tema poderia dar margem a reações político-ideológicas e sofrer restrições editoriais pela censura vigente. Então, decidi enviar o original para algumas editoras nacionais para testar o possível interesse. Na realidade, fui surpreendido pelo retorno positivo de todas elas. Daí ter tido a possibilidade de escolher a mais conceituada academicamente-a Difusão Europeia do Livro-especializada na publicação de livros de ciências humanas, principalmente da USP, sob a direção do sociólogo Fernando Henrique Cardoso. Algumas editoras, no afã de publicarem rapidamente o livro, propunham-se a traduzir a tese tal qual. Não aceitei porque haveria uma distorção entre os textos originais e os vertidos por mim para o francês. Tal preocupação obrigoume a dedicar vários meses a uma cuidadosa tradução, com a incorporação dos originais, assegurando maior qualidade à publicação. A primeira edição esgotou-se em menos de três meses. Devo ressaltar que imprensa do Rio (Jornal do Brasil) e de São Paulo ("Estadão") fizeram destacadas matérias em cadernos especiais, ilustradas e com listas de dirigentes e militantes da AIB. O livro ficou entre os mais vendidos por muitas semanas.

Obviamente, esse alto interesse tinha muito a ver com a conjuntura política: o regime militar e a presença de muitos ex-dirigentes da AIB em postos políticos importantes do governo. Refiro-me ao ex-chefe nacional da AIB, Plínio Salgado, que era deputado federal da ARENA; Raimundo Padilha, chefe nacional durante o exílio de Salgado em 
Portugal, líder da ARENA na Câmara de Deputados; o Ministro da Justiça, o jurista Alfredo Buzaid; sem esquecer do protagonismo do Gal. Olympio Mourão Filho, comandante da milícia da AIB, que desencadeou o golpe, com suas tropas vindas de Juiz de Fora (MG) sobre o Rio de Janeiro.

As críticas à publicação do meu livro - Integralismo: o fascismo brasileiro da década de 30 - foram, em geral, muito positivas. No Brasil, foi bem acolhida nos meios acadêmicos como uma contribuição que veio preencher uma lacuna na literatura pertinente e, no exterior, a AIB foi incorporada aos estudos comparativos, nas análises históricas sobre o fascismo internacional. Por outro lado, é importante ressaltar que não houve qualquer tipo de crítica fora da academia ou na imprensa sobre o tema, em função do regime militar vigente. Creio que seu forte conteúdo acadêmico explica sua excepcional recepção, na conjuntura política de sua publicação.

- E quais foram as reações do mundo acadêmico?

- Antes de retornar ao Brasil enviei alguns exemplares da tese, em sua versão francesa, para um pequeno grupo de acadêmicos no Brasil e exterior pedindo seus comentários. No exterior refiro-me, entre outros, a Gino Germani, sociólogo argentino, com obra clássica sobre o peronismo; Juan Linz, da Universidade de Yale, com contribuição importante nos estudos comparativos sobre o fascismo; Stanley Payne, historiador americano e autor de obra de referência sobre a historia do fascismo, incluindo o Integralismo entre os fascismos extra-europeus; Pierre Milza, historiador francês especialista no fascismo italiano e fascismo internacional e Thomas Skidmore, historiador americano e brasilianista que havia citado a tese de Hunsche.

No Brasil, enviei para o professor Cruz Costa, do Departamento de Filosofia da USP, que publicou livro clássico sobre ideias políticas, com ênfase no positivismo; Edgard Carone, historiador da USP com obra inovadora sobre as articulações entre instituições políticas e movimentos no período de 1920 e 1940; o economista, Celso Furtado, professor da Universidade de Paris e integrante da minha banca de doutorado; Alceu Amoroso Lima, o mais influente líder católico, dirigente do Centro Dom Vital e da Revista A Ordem. A transcrição de alguns desses comentários positivos, na orelha do livro, contribuíram muito para legitimá-la junto aos leitores.

Cabe ressaltar que a reação acadêmica foi muito favorável entre a comunidade das ciências humanas por ser uma tese que se utilizou 
de um enfoque interdisciplinar para a validação das hipóteses: desde a análise clássica do discurso ideológico, passando pela abordagem sociológica da base social até o campo da psicologia social com análises de atitudes e motivações de adesão. Alguns colegas usaram o livro para o ensino da pesquisa qualitativa e quantitativa. $\mathrm{Na}$ realidade, o único trabalho que teve por ambição ser a antítese da minha tese, foi o de José Chasin em 1978 (O Integralismo de Plínio Salgado: forma de regressividade no capitalismo hipertardio). Chasin adotou uma abordagem teórico-metodológica que referendasse a impossibilidade de um movimento fascista no Brasil, usando, de forma dogmática, a posição do teórico marxista G. Luckacs: num país de capitalismo hipertardio não poderia haver fascismo. Toda sua pesquisa e análise foi um esforço para negar qualquer conteúdo fascista à AIB em decorrência de sua premissa dogmática. Ademais, para tal demonstração, utilizou apenas a obras de Plínio Salgado, excluindo as contribuições de Miguel Reale, Secretário Nacional de Doutrina, e Gustavo Barroso, cujas obras inspiravam-se, respectivamente, nos teóricos do fascismo italiano ou no ideário nazista, com forte conteúdo antissemita.

Recente tese de doutorado defendida na UFRJ, em 2013, por Alexandre Pinheiro Ramos (Intelectuais e carisma: a Ação Integralista Brasileira na década de 1930), dedica um capítulo à recepção da minha tese no Brasil. Sua crítica é curiosamente paradoxal: ao reconhecer a quase unanimidade da aceitação da minha tese pelos autores que produziram vasta bibliografia posterior sobre a AIB, sugere que ela deixou de ser "científica" e entrou no domínio do "sagrado". Esse princípio parece bastante questionável: significaria que o conteúdo de um livro (tese) perde sua "cientificidade" em função de sua ampla aceitação!? A meu ver, a explicação é mais simples: como obra pioneira foi sempre citada por autores focados em estudos regionais, mas isto não significou, necessariamente, a aceitação tácita do seu conteúdo nacional e internacional.

A tese de Ramos utiliza sofisticada bibliografia de apoio, mas não conseguiu demonstrar sua hipótese sobre a natureza eminentemente intelectual da AIB. Se na fase da implantação do movimento, em alguns Estados, houve um debate intelectual diletante que poderia justificar a hipótese, num segundo tempo as discussões tornam-se políticas ao destinarem-se a fazer proselitismo e recrutar adeptos. A missão do Integralismo era de criar um movimento político-ideológico em que a literatura e o debate intelectual foram instrumentalizados para esse objetivo. Tal dinâmica desdobrou-se em diferentes etapas do 
governo Vargas: primeiro com os editoriais de Salgado no jornal $A$ Razão para influenciar, sem sucesso, o Chefe do Governo Provisório; segundo, e como epilogo, após a Marcha sobre a Guanabara, atacar com armas o Palácio Presidencial, após se sentirem traídos pelo Chefe do Estado Novo. Obviamente que a tese, embora trazendo uma discussão interessante sobre o papel do "carisma", não tem êxito em sua demonstração.

- Um dos estudos posteriores ao seu - ainda na década de 1970 - foi o de Gilberto Felisberto Vasconcellos, intitulado A ideologia curupira. No prefácio a ele, Florestan Fernandes escreveu: "Hoje está na moda dizer-se que se deve estudar o integralismo. Não compartilho dessa opinião". O Senhor se sentiu atingido por essa observação? - Constato que o prefácio de Florestan Fernandes foi escrito cinco anos após a publicação do meu livro. Participei da banca de Vasconcellos em seu doutorado na USP e na minha arguição valorizei sua criatividade intelectual e originalidade. Essa frase de nenhuma forma seria dirigida a mim, nem ao próprio autor, pois se este pudesse ser o desígnio de Florestan não seria razoável que aceitasse escrever o referido prefácio.

No entanto, é preciso reconhecer que, essas duas teses, defendidas na USP, são tardias. Os professores da instituição não se ocuparam da AIB como movimento nascido em território paulista, mas optaram por outros temas, provavelmente mais estratégicos para o desenvolvimento das respectivas áreas. Em consequência, as teses tardias de Chasin e Vasconcellos, tentaram recuperar o distanciamento da USP com relação ao tema, que acabou sendo pesquisado e analisado por um professor de outra instituição. Às vezes, um certo "patriotismo institucional" pode explicar frases do gênero.

Lembro-me sempre do entusiasmo de Edgard Carone quando tomou conhecimento da minha tese ainda em francês. Utilizou generosas citações em um dos seus livros sobre a República Nova, pós-1930. Em nossas longas conversas sempre valorizou o conteúdo do livro, apenas discordou de uma passagem em que eu afirmava ser a AIB o primeiro "partido de massa" no Brasil. Ele reagiu e afirmou que este seria o PCB. Era ideia vigente na época que um partido de "massa" teria de ser de esquerda. Carone não se tinha dado conta de que o suporte empírico da afirmação decorria do tipo de implantação nacional da AIB, num período em que o PCB possuía uma base social e política regionalizada, como era o caso também dos partidos republicanos oligarquizados. 
- Qual é sua opinião sobre os estudos em torno do integralismo da "primeira geração" (década de 1970), que, afinal, escrevia seguindo ou criticando as "pegadas" deixadas por seu trabalho pioneiro?

- As duas teses da "primeira geração" já foram referidas (José Chasin e Gilberto Vasconcellos), mas não poderia deixar de mencionar duas outras contribuições relevantes e abrangentes: a de Marilena Chauí em 1978 (Apontamentos para uma crítica da Ação Integralista Brasileira) e posteriormente, a tese de Rosa Maria Cavalari, de 1999 (Integralismo: ideologia e organização de um partido de massa no Brasil, 1932-1937).

$\mathrm{O}$ primeiro texto foi inserido num livro publicado pelo CEDEC, sob o título Ideologia e Mobilização Popular, no qual Chauí critica os estudos "que não consideram sua relevância analítica; quando fazemos análise ideológica, tendemos esquecer essas formas da existência social que são o pensamento e as representações." O título despretensioso de "Apontamentos para uma crítica da Ação Integralista Brasileira" não corresponde à qualidade do ensaio que penetra em profundidade no universo da literatura sobre e dos integralistas. Baseando-se ora em enfoque filosófico, ora tomando os escritos dos ideólogos do Integralismo, Chauí discute, na primeira parte, as complexas relações entre a AIB e as "classes médias" no período, para responder à questão: qual o "destinatário do discurso integralista"? Na segunda parte, desenvolve uma análise instigante, apoiada em textos de Salgado e Reale, sobre os usos da "imagem da crise" (conjuntural, estrutural, mundial e de civilização) como "tema mobilizador" no discurso integralista. Esta construção ideológica abriu duas possibilidades na lógica integralista: de um lado, "suscitou a criação de mitos para legitimar burgueses bem pouco heroicos"; de outro, ofereceu à "classe media uma ideia-força propícia ao heroísmo, mas capaz de ao mesmo tempo de ser "varonil" e "apaziguadora" para classe media "portadora da Ideia."

Noutra perspectiva, a tese de Cavalari introduziu um novo ângulo nas pesquisas sobre a AIB, numa perspectiva nacional. Partiu de minha análise sobre do Integralismo como "partido de massa", mas explorou de forma mais aprofundada todas as formas de transmissão da doutrina nos diferentes níveis da organização (nacional, provincial ou local), pela estratégica distribuição dos livros e pela veiculação ideológica através da imprensa nacional e regional. Trouxe outra contribuição importante sobre a ação social e educacional da AIB, dentro da concepção de uma "educação integral" que, segundo Cavalari "não deve se despreocupar de nenhuma de suas facetas, deve ser física, cientifica, artística, econômica, social, política e religiosa". 
Ressalte-se também que na UFRGS foram produzidas as primeiras dissertações de mestrado, sob minha orientação, sobre a AIB numa perspectiva regional. A primeira de René Gertz (1977) abordando as relações entre nazismo, germanismo integralismo na região de colonização alemã no RS e, a segunda, de Carla Brandalise, mais abrangente, sobre o Integralismo no RS (1992). Essas duas dissertações foram pioneiras nos estudos regionais sobre a AIB e, provavelmente, influenciaram a excepcional onda posterior de estudos na área.

Considero necessário que, sobre uma problemática complexa como a da AIB, novas pesquisas, com outras abordagens, explorem o tema em diferentes ângulos analíticos. Foi o que fizeram os autores das duas teses da USP, embora nenhum deles tenha se colocado na perspectiva sociológica ou da ciência política. Minha avaliação é que, além da "primeira geração", as seguintes produziram uma vasta bibliografia que, sem entrar no mérito de sua qualidade, certamente enriqueceu o conhecimento da AIB, em suas diferentes implantações locais. Apesar da homogeneidade ideológica que teve a AIB, resultante de sua estrutura hierárquica rígida e a eficaz socialização doutrinária em todos os níveis, o contexto regional e suas diferentes tradições políticas tiveram um papel importante no padrão das chefias e militâncias locais. Esta realidade apareceu, claramente, na análise das entrevistas dos dirigentes e militantes locais. Parece plausível que um integralista da região alemã ou italiana do Rio Grande do Sul e Santa Catarina tenha um perfil diferente do padrão médio dos militantes da Bahia ou do Ceará. Neste sentido, todos esses trabalhos contribuíram para uma análise mais rica e abrangente. Espero que no futuro, na medida em que os resultados dessas pesquisas regionais e locais forem cumulativos, permitam outros trabalhos numa perspectiva nacional.

- Nos últimos 45 anos, os estudos sobre o integralismo se multiplicaram às centenas. $O$ Senhor arrisca uma opinião sobre quanto há aí de "joio" e quanto há de "trigo", entre eles? Poderia citar alguma(s) direção(ões) de estudos que trouxeram contribuições relevantes, e, inversamente, direções que não levaram a resultados significativos?

- Impressionante é o volume de estudos regionais sobre o Integralismo, reunidos por João Bertonha, da Universidade de Maringá, em sua Bibliografia Orientativa sobre o Integralismo (1932-2007). Por sua vez, Giselda da Silva Brito, da UFRPE, fez também um amplo balanço da produção sobre a AIB em seu livro de 2007, Estudos de Integralismo no Brasil. Na realidade, não tive condições de acompanhar no detalhe 
essa literatura, produzida por uma nova geração de pesquisadores, organizados junto à ANPUH e ao $\mathrm{CNPq}$, na medida em que fui me envolvendo em outras áreas da ciência política, mais voltadas para o processo de redemocratização do país. Agora, depois de mais de quatro décadas da publicação da primeira edição de meu livro, em 1974, volto ao tema para escrever um novo livro analisando as entrevistas com dirigentes nacionais, regionais e dirigentes e militantes locais da AIB.

Achei muito consistente, também, o balanço realizado por Rodrigo Santos de Oliveira, da Universidade Federal do Rio Grande, em artigo de 2010 na Estudos Ibero-Americanos (A Evolução dos Estudos sobre o Integralismo) ao analisar as diferentes etapas das pesquisas sobre a AIB. O autor partiu dos estudos nacionais e debruçou-se sobre a grande profusão de estudos que ele denominou $O$ integralismo organizado regionalmente e as novas abordagens adotadas nas pesquisas. Considero que também contribuíram para essa nova fase as dissertações de René Gertz (1977) e Carla Brandalise (1992), por mim orientadas. A partir daí começou a emergir um conjunto de estudos sobre outros Estados até então pouco estudados, especialmente no Nordeste. Os resultados dessas pesquisas e publicações enriqueceram o conhecimento da AIB em sua ação local. Naturalmente, houve uma rica descoberta do perfil dos dirigentes e militantes locais que, embora enquadrados pelo comando nacional e regional, através dos livros, revistas e jornais, construíram formas de militância política e ação social influenciadas pelo contexto regional/local. Esses estudos mostraram a riqueza das experiências marcadas por sua inserção regional, rural ou urbana, nas zonas de imigração estrangeira ou regiões de população dominantemente "brasileira", assim como suas relações com a política municipal e seus conflitos, relações com a Igreja etc.

Neste sentido, não tenho como estabelecer esse balanço entre o "joio" e o "trigo", mas tendo a olhar positivamente o conjunto da obra dessa nova etapa. Nem todos os trabalhos são de qualidade, como ocorre em qualquer área, mas essa cumulatividade de conhecimento é rica e incorporou seriamente o Integralismo na agenda de pesquisa brasileira.

- As entrevistas com ex-militantes da AIB constituem parte muito importante do seu trabalho. Poderia relatar como chegou aos entrevistados? Que dificuldades encontrou? A então recente extinção do PRP - o sucedâneo da AIB - favoreceu ou prejudicou a tentativa? Há algum episódio marcante, sob essa perspectiva? 
- $\mathrm{Na}$ época em que realizei a pesquisa de campo, reunindo documentação sobre a AIB, fiz um roteiro para uma entrevista não diretiva de longa duração e um questionário com uma bateria de questões para estabelecer o grau de adesão dos integralistas aos grandes temas da ideologia fascista. Os resultados da pesquisa realizada através dos questionários analisei exaustivamente na tese, eles permitiam avaliar o grau de aderência dos integralistas à ideologia, elaborada quatro décadas antes e, ao mesmo tempo, identificar seu grau de identidade com dimensões clássicas da ideologia nazifascista europeia. Essa análise foi crucial para viabilizar a comparabilidade entre a AIB e outros movimentos europeus do gênero, inspirados no Partido Nacional Fascista italiano (PSI) e no Partido Nacional Socialista dos Trabalhadores Alemães (NSDAP). Os dados levantados pela pesquisa permitiram reconstituir a base social da AIB, nos diferentes níveis da hierarquia, e sua comparabilidade com dados do mesmo tipo de outros partidos nazifascistas, como o fez Juan Linz, incluindo a AIB em sua comparação internacional.

Iniciei meus primeiros contatos com os dirigentes e militantes em Porto Alegre, apresentando minhas credenciais como professor da UFRGS. Esse detalhe facilitou as primeiras entrevistas, começando com o Chefe Provincial do Rio Grande do Sul, Dario Bittencourt, que fora professor da Faculdade de Direito desta mesma universidade. Reconheço que esse fator foi importante na estratégia das entrevistas: sempre fui bem recebido pelos integralistas, sem nenhum tipo de desconfiança e, poderia dizer, até com certa simpatia por serem valorizados num trabalho realizado para uma universidade europeia. Bittencourt foi um ponto de partida importante para mapear uma primeira lista de contatos com os entrevistados, identificar os que ainda estavam vivos, inclusive fornecendo os endereços e telefones. Com essa legitimidade pude circular entre os integralistas sem nenhuma dificuldade. Nenhum dos nomes indicados recusou-se a conceder a entrevista gravada. Pouco a pouco, com a familiaridade do tema, eu desenvolvia os diálogos, já sintonizado com o jargão dos dirigentes/militantes, o que facilitava a comunicação com eles. Alguns entrevistados perguntaram, inclusive, se eu estava fazendo essa pesquisa para refundar a AIB.

Outro fator contextual importante foi a própria ditadura militar, com a qual a grande maioria dos entrevistados estava fortemente identificada. Suas atitudes eram motivadas pela ideia de que o regime estava colocando em prática muitas "bandeiras" frustradas historicamente pelo fechamento da AIB, em 1938. Essa conjuntura política estimulava-os a falar com 
mais abertura e, poderia afirmar mesmo, ter sido este um elemento muito favorável ao desenvolvimento da pesquisa entre 1968 e 1970.

No Rio de Janeiro os integralistas mais ativos estavam identificados com a "linha dura" militar, apoiando a candidatura nacionalista do Gal. Albuquerque Lima, ex-ministro da Integração, contra a de Garrastazu Medici, na disputa interna das Forças Armadas. Organizavam cursos sobre a "doutrina integralista" para fazer proselitismo, visando angariar adeptos. Em São Paulo, o clima político era igualmente tenso como no Rio, mas não havia ligações tão diretas com os militares e as entrevistas transcorreram normalmente, com alguns episódios politicamente "pitorescos", como relatei no novo livro e que seria longo incluir nesta resposta. Todos esses fatores conjunturais favoreceram a disposição dos militantes a relatarem seus engajamentos na AIB.

- Entre os entrevistados sobressai, naturalmente, Plínio Salgado, o "chefe nacional". Como foi a aproximação com esse candidato a entrevistado, como transcorreu a entrevista?

- Em São Paulo, o dirigente da AIB mais relevante para a minha pesquisa foi Rui Arruda, responsável pela "Casa Civil" do Chefe Nacional. Deu-me acesso a materiais importantes: uma biografia de Salgado reconstituindo etapas importantes do seu itinerário político ideológico, desde a época dos movimentos modernistas, sua viagem à Itália onde entrevistou Mussolini, até sua atividade jornalística no jornal A Razão. O mais importante, porém, foi a doação de cópia datilografada de todos os editoriais de Salgado, no referido jornal, o que me permitiu estabelecer as linhas mestras do ideário "pré-integralista". Além disso, ele tinha uma biblioteca com todos os livros que eram lidos, à época, pela geração de jovens intelectuais, dirigentes e militantes integralistas e permitiu que eu os consultasse, livremente, em seu gabinete durante vários dias. Essa oportunidade deu-me uma visão compreensiva dos livros nacionais e internacionais relevantes sobre os fascismos, o pensamento de extrema-direita europeu, a literatura brasileira dos "ensaístas" do pensamento autoritário e até mesmo livros marxistas traduzidos.

Esse dirigente nacional foi de grande valia para os contatos com dirigentes nacionais, principalmente com o próprio Plínio Salgado. Ele tomou a iniciativa de contatá-lo, marcando a data da entrevista em Brasília, com a preocupação de que eu não deixasse passar muito tempo, sob o risco de perder essa entrevista fundamental, devido à fragilidade da saúde do Chefe. Fui a Brasília e, na véspera, telefonei para 
ele informando que estava no hotel. Consultei sobre o melhor horário para a entrevista na manhã do dia seguinte. Respondeu-me que não podia me receber pela manhã, mas somente no final da tarde, porque tinha vários compromissos urgentes. No horário aprazado fui recebido por sua esposa, D. Carmela, e ele apareceu, de chambre, no fundo da sala. Solicitou que não me aproximasse porque estava muito gripado. Logo decifrei a charada, pelas informações que me haviam dado em São Paulo: ele estava com um problema de alcoolismo crônico. Achei que havia perdido a viagem. Mas devo confessar que, após ter feito uma pergunta sobre o significado do nacionalismo para o Integralismo, impressionou-me sua memória e o tom oratório em que desenvolveu sua resposta. Foi uma entrevista muito boa. Depois, marcamos uma segunda em sua casa em São Paulo. Esta foi extraordinária: além de introduzir novas questões, ele viabilizou o aprofundamento da primeira. O ponto alto foi nosso diálogo sobre o significado de sua experiência como chefe nacional da AIB. Essas duas entrevistas foram transcritas e são comentadas em meu novo livro. É o depoimento central e o único identificado. Nos outros preservei o anonimato prescrito academicamente em pesquisas do gênero. Fiz um perfil detalhado de cada um e coloquei a listagem dos integralistas no anexo bibliográfico.

- Da liderança "trinitária" da AIB (Plínio Salgado, Gustavo Barroso, Miguel Reale), só estavam vivos o primeiro e o último. Este, não aderiu ao PRP, no pós-guerra. Qual foi a tônica das suas respostas, na entrevista?

A entrevista de Miguel Reale - que na época era Reitor da USP - foi a mais difícil de ser obtida e a mais relevante pelo conteúdo do depoimento. A primeira reação, ainda no elevador a caminho do seu gabinete, foi a de que não daria entrevista sobre a AIB "a um jovem professor interessado em agradar os meios universitários de esquerda na França." Eu ainda não tinha entrevistado Salgado, mas consegui, com muita dificuldade, usando toda a minha capacidade persuasiva, demovê-lo da ideia inicial e reduzir sua resistência. Isto ocorreu quando me convidou a sentar no seu gabinete e passou a justificar sua reação primeira, buscando explicar sua posição de ex-Secretário Nacional de Doutrina da AIB.

Reale procurou deixar bem claro que, embora jovem jurista e filho de italianos natos, teve acesso aos livros dos teóricos do corporativismo italiano: Alfredo Rocco e Giuseppe Bottai. Produziu 
livros com sólido suporte teórico que não se confundiam com os textos de "vulgarização" ideológica de Salgado. Este, segundo Reale, não ia às fontes, aos autores, mas aprendia de segunda mão, embora fizesse boas sínteses com seu talento de escritor. Como o Reitor da USP, Reale tinha uma carreira acadêmica consolidada na Filosofia do Direito, era tido como um teórico reconhecido e, aparentemente, ao afastar-se da AIB rompera com qualquer laço, mesmo com o sucedâneo político, o Partido de Representação Popular (PRP). Inscreveu-se no Partido Social Progressista, de Ademar de Barros, optando por um partido considerado mais populista do que o fundado por Plínio Salgado.

Sua entrevista, na realidade, objetivou explicar as confusões conceituais e históricas sobre fascismo e integralismo. Seu raciocínio legitima, de certa maneira, as relações entre a AIB e o fascismo italiano, do qual ele foi um dos mais sólidos defensores. Argumenta que o período de existência da AIB (1932-1938) corresponde à fase em que o fascismo italiano, e seu chefe Benito Mussolini, estavam em plena ascensão política e ideológica. $\mathrm{Na}$ época, tinham a simpatia de vários países, inclusive da Inglaterra. Não tinha havido ainda nem a invasão imperialista da Etiópia, nem a aliança com o regime hitlerista. Todos esses episódios ocorreram depois que o Integralismo foi fechado pelo Estado Novo, em 1938, com o fracassado atentado contra Vargas. Seu argumento é que o anátema do fascismo foi produto desse segundo período, com seus desdobramentos durante a Segunda Guerra Mundial e a derrota do Eixo. Nessa perspectiva analítica admite, implicitamente, que nesse período do regime fascista, a influência da experiência fascista do Estado corporativo foi naturalmente assimilada pelos teóricos, dirigentes e militantes da AIB. Hoje, a percepção da AIB não leva em conta essa cronologia e confunde os fatos.

- O Senhor está trabalhando na edição das entrevistas feitas mais de 45 anos atrás. Por que essa demora na publicação? Houve exigências de parte dos entrevistados para que fossem publicadas somente após sua morte? Ou o Senhor sentiu uma necessidade pessoal para publicá-las agora? Os termos das entrevistas trarão detalhes novos sobre o tema? Caso positivo, pode adiantar algum(ns)? A publicação reproduz a totalidade e a íntegra das entrevistas, ou parte continuará inédita?

- As razões desse longo lapso temporal não podem ser reduzidas aos termos da pergunta. O principal foi o de respeitar o pedido da maioria dos entrevistados de que não publicasse as mesmas enquanto 
estivessem vivos. Foi um compromisso moral que cumpri rigorosamente. Hoje todos já faleceram. Outras razões estão relacionadas às novas áreas de interesse no ensino e pesquisa. Do Integralismo fui para campos novos, tais como a transição e consolidação da democracia, partidos políticos, eleições, positivismo e história política do RS. A partir de 2000, fui, várias vezes, pesquisador-visitante da École des Hautes Études en Sciences Sociales de Paris, e lancei-me numa ambiciosa pesquisa sobre ciências sociais na América Latina em perspectiva comparada. Vários livros foram publicados no Brasil e no exterior, tornando-se o tema central da minha atividade acadêmica atual. Apesar do sucesso do livro da AIB, que marcou o início da minha carreira universitária, ele não limitou os meus interesses acadêmicos.

Mantive, no entanto, o compromisso de analisar o acervo de entrevistas dos integralistas, respeitando as regras do jogo, mas muitas vezes não tinha disponibilidade e fôlego para enfrentar a densidade do complexo do desafio. A demora na publicação poderia ter sido menor, mas assumi, em 2008, o compromisso de colaborar na construção de uma nova universidade federal brasileira com vocação latino-americana (UNILA), situada em Foz Iguaçu, o que me obrigou a uma dedicação plena ao novo projeto. Agora, retornando à UFRGS, fiquei disponível para retomar a análise desse acervo único de entrevistas. O novo livro, de 838 páginas, foi escrito entre janeiro e outubro de 2015.

Em 1997, quando passei um ano na Universidade de Stanford, tive consciência do valor de meu acervo quando o Hoover Institutions Archives manifestou interesse em comprá-lo. Eles possuem o único acervo de depoimentos escritos de nazistas, levantados antes da II Guerra por um professor da Universidade de Columbia. Boa parte desses documentos (3800) foi apreendida pelo FBI para persegui-los no após guerra. Esta documentação viabilizou uma única tese do gênero, de autoria de Peter Merkl.

De retorno à UFRGS, no final de 2014, recebi de Alexandre Ramos cópia da tese já referida. Seu capítulo sobre recepção do meu livro, quarenta anos depois, instigou-me a voltar ao tema novamente. Em 2015, escrevi o novo texto, tendo como núcleo central a análise das entrevistas. Neste momento o livro está no prelo da editora da UFRGS e deve ser lançado em abril deste ano.

O livro reúne o conjunto de entrevistas com dirigentes nacionais, regionais e locais, além de uma série de depoimentos de intelectuais não integralistas que foram contemporâneos da AIB: Antônio Candido, 
Alceu Amoroso Lima, Menotti del Pichia, entre outros. No livro explico os critérios utilizados na elaboração da estratégia de análise das entrevistas e depoimentos.

- Mesmo que o Senhor tenha transitado por um grande número de campos e de temas da Ciência Política, não há dúvida de que sua biografia intelectual está marcada pelo integralismo, e o Senhor sempre de novo retornou a ele. Por que valeu investir tanto tempo e esforço nesse tema?

- Certamente a circulação internacional da minha tese e a sua bem sucedida publicação no Brasil marcaram fortemente o início da minha carreira acadêmica, mas eu não diria que foi o tema mais importante da minha biografia intelectual. Os outros temas em que investi têm a ver com a própria dinâmica da política brasileira. Pesquisei e publiquei, com colegas da área, sobre temas que considero importantes no sentido de contribuir para a redemocratização e a consolidação democrática em nosso país.

- Qual das entrevistas foi a mais bem sucedida e qual a mais decepcionante?

- Além das já referidas entrevistas de Plínio Salgado, Miguel Reale e Rui Arruda, no plano nacional, e Dario Bittencourt, por seu papel de destaque na Chefia da Província do Rio Grande do Sul, houve um grupo importante de intelectuais e dirigentes da AIB que deram bons depoimentos. No Nordeste, uma das mais substanciosas entrevistas foi a de Jeová Mota, dirigente da AIB do Ceará, originário da Legião Cearense do Trabalho, que fora fundada, em 1931, pelo Tenente Severino Sombra. Tive grande dificuldade em localizar Jeová Mota porque os integralistas não tinham interesse que eu obtivesse o seu depoimento. Ele foi deputado federal pela AIB, eleito em 1934, e desautorizado publicamente pelo Chefe Nacional ao tentar dar uma base sindical à AIB (como fora a experiência da Legião no Ceará). Mota renuncia à Secretaria Nacional de Relações Sindicais e ao mandato de deputado federal, evoluindo para uma posição ideológica de esquerda.

O depoimento de Jeová foi de grande transparência porque não buscou subterfúgios. Declarou que no Ceará fora muito influenciado pelo Pe. Hélder Câmara, que o transformou num tenente engajado, e que tinha optado, à época, pela ideologia fascista diante da polarização com os comunistas. Seria longo reproduzir a riqueza desse testemunho, 
mas permitiu a compreensão de várias questões aclaradas ao longo da pesquisa.

Não houve entrevista decepcionante, mas a qualidade dos depoimentos era diferenciada em função do nível político, cultural e educacional dos entrevistados. Mesmo nos casos de militantes locais, com uma visão mais restrita, sempre havia aspectos dos depoimentos que contribuíram para a visão do conjunto.

Tenho a convicção de que meu novo livro (A tentação fascista no Brasil: imaginário de dirigentes e militantes integralistas) vai oferecer aos estudiosos do integralismo no Brasil e do fascismo extraeuropeu a análise sistemática de um acervo de depoimentos que confirmarão de forma mais contundente ainda, a hipótese fascista proposta no meu livro de 1974, agora tendo como objeto de análise os próprios dirigentes e militantes da AIB.

A publicação deste livro encerrará minhas pesquisas e análises sobre o Integralismo. Considero que não tenho mais nada de relevante a agregar sobre o tema. Meu acervo pessoal - livros integralistas, documentação, jornais, minha biblioteca especializada sobre o fascismo internacional e o arquivo sonoro das entrevistas e depoimentos - será doado à Unicamp, integrado ao Arquivo Edgard Leuenroth, assegurando o livre acesso aos pesquisadores interessados no tema. Afinal, a AIB, por suas origens é um movimento e um partido do Estado de São Paulo. Penso que meu acervo será bem preservado numa das mais prestigiosas universidades brasileiras. 


\section{Autores/Authors:}

RENÉ E. GERTZ<gertz@pucrs.br>.

- Professor Titular do PPG-História da Pontifícia Universidade Católica do Rio Grande do Sul (PUCRS) e professor-associado (aposentado) pela Universidade Federal do Rio Grande do Sul (UFRGS). Doutor em Ciência Política pela Freie Universität Berlin. Tem experiência na área de História do Brasil-República, com interesse especial por aspectos políticos do processo de imigração e colonização no sul do Brasil, por integralismo, por nazismo, por germanismo, por neonazismo, por protestantismo, por preconceitos étnicos e religiosos, pela política gaúcha do período em torno do Estado Novo (1937-1945). Além disso, tem dedicado atenção à historiografia alemã contemporânea, tentando divulgá-la no Brasil, principalmente, através de traduções. Autor de vários artigos científicos, publicou os livros O neonazismo no Rio Grande do Sul (EdiPUCRS; AGE, 2012), O perigo alemão (Editora da UFRGS, 1998) e O fascismo no sul do Brasil (Mercado Aberto, 1987).

- Full professor of the Graduate Program in History at Pontifícia Universidade Católica do Rio Grande do Sul (PUCRS) and associate professor (retired) at Universidade Federal do Rio Grande do Sul (UFRGS). PhD in Political Science from the Freie Universität Berlin (FU-Berlin). He has experience in researching the History of Republican Brazil, particularly the political aspects of immigration and colonization processes in southern Brazil. He is also interested in the History of Integralism, Nazism, Germanism, Neo-Nazism, Protestantism, and the regional politics in Rio Grande do Sul during Vargas' New State (1937-1945). Moreover, he has devoted attention to contemporary German historiography, translating many papers from German into Portuguese. Author of several scientific papers, René Gertz has published the following books: O Neonazismo no Rio Grande do Sul (EdiPUCRS/AGE, 2012), O Perigo Alemão (Editora da UFRGS, 1998) and Fascismo no Sul do Brasil (Mercado Aberto, 1987).

LEANDRO PEREIRA GONÇALVES <leandro.goncalves@pucrs.br>.

- Professor adjunto do Programa de Pós-Graduação em História da Pontifícia Universidade Católica do Rio Grande do Sul (PUCRS). Doutor em História pela Pontifícia Universidade Católica de São Paulo (PUC-SP) com estágio (Junior Visiting Fellow) no Instituto de Ciências Sociais da Universidade de Lisboa (ICS-UL) e com pós-doutoramento pela Universidad Nacional de Córdoba (Centro de Estudios Avanzados/Argentina). É Investigador Estrangeiro Associado ao Centro de Estudos de História Religiosa da Universidade Católica Portuguesa (CEHR/UCP). Líder do Grupo de Pesquisa (CNPq), Portugal e Brasil no Mundo Contemporâneo: identidade e memória e coordenador da rede de investigação, Direitas, História e Memória. Publicará em 2017 o livro Plínio Salgado. Um Católico integralista entre Portugal e o Brasil (1895-1975), que é resultado da premiada tese de doutoramento, Entre Brasil e Portugal: trajetória e pensamento de Plínio Salgado e a influência do conservadorismo português. As pesquisas recentes concentram-se em questões relacionadas à compreensão do conservadorismo do século $\mathrm{XX}$, o estudo da direita, cristianismo e autoritarismo, fascismo, integralismo, ações imigrantistas e nos aspectos teorizados através da cultura política, tendo como foco os elementos transnacionais existentes entre a Península Ibérica e a América Latina. É autor de diversos artigos científicos, além de ser autor e organizador de vários livros acadêmicos, com destaque para Presos Políticos e Perseguidos Estrangeiros na Era Vargas (Mauad X, 2014) e Entre Tipos e Recortes: Histórias da imprensa integralista (2 vols.) (Sob Medida, 2011-2012).

- Associate Professor of the Graduate Program in History at the Pontifícia Universidade Católica do Rio Grande do Sul (PUCRS). $\mathrm{PhD}$ in History from the Pontifícia Universidade Católica de São Paulo (PUC-SP) with a Junior Visiting Fellowship at the Institute of Social Sciences, at the Universidade de Lisboa (ICS-UL) and post-doctorate from the Universidad Nacional de Córdoba (Centro de Estudios Avanzados / Argentina). Associate foreign investigator to the Centre for Studies in Religious History at the Universidade Católica Portuguesa (CEHR / UCP). Leader of the research group (CNPq) "Portugal and Brazil in the Contemporary World: Identity and Memory" and coordinator of the research network "Right Wings, History and Memory". He is going to publish in 2017 the book Plinio Salgado: Um Católico Integralista entre Portugal e o Brasil (1895-1975), which is the result of his award-winning doctoral thesis. His recent researches have focused on the conservatism in the twentieth century, the study of the right-wing, christianity and authoritarianism, fascism, integralism and theorized aspects through political culture, focusing on the transnational elements between Iberia and Latin America. He is the author of several scientific papers, as well as organizer of many scholarly books, particularly Presos Politicos e Perseguidos Estrangeiros na Era Vargas (Mauad X, 2014) and Entre Tipos e Recortes: Histórias da imprensa integralista (2 vols) (Sob Medida, 2011-2012).

VINÍCIUS LIEBEL < v.liebel@uol.com.br>

- Professor Colaborador do PPG-História da Pontifícia Universidade Católica do Rio Grande do Sul (PUCRS) e bolsista Capes/ PNPD na mesma instituição. Historiador, doutor em Ciência Política pela Freie Universität Berlin (FU-Berlin) com bolsa do Deutscher Akademischer Austauschdienst (DAAD) e pós-doutor pela Universidade de São Paulo (USP) com suporte da Fundação de Amparo à Pesquisa do Estado de São Paulo (Fapesp). Dedica-se à pesquisa em História Contemporânea e em História do Brasil República, com ênfase nas décadas de 1930-60. Entre os temas mais trabalhados estão Nazismo, Antissemitismo, Germanismo, Fascismo, Estado Novo, Totalitarismo, Conservadorismo e Humor e Política. A análise de imagens, em especial das charges, assim como a teoria e metodologia que a envolvem, também são seus temas de pesquisa. É autor do livro Politische Karikaturen und die Grenzen des Humors und der Gewalt (Budrich Verlag, 2011).

- Lecturer of the Graduate Program in History at the Pontifícia Universidade Católica do Rio Grande do Sul (PUCRS) and post-doctoral researcher at the same institution, with a Capes/PNPD scholarship. Historian, PhD in Political Science from the Freie Universität Berlin (FU-Berlin) supported by a DAAD (Deutscher Akademischer Austauschdienst) scholarship. He was a post-doctoral fellow at the Universidade de São Paulo (USP) and was supported by a scholarship from the Fundação de Amparo à Pesquisa do Estado de São Paulo (Fapesp). Vinícius Liebel's main themes of research are Contemporary History and History of Republican Brazil, emphasizing the decades of 1930-60. Nazism, Anti-Semitism, Germanism, Fascism, Vargas' New State, Totalitarianism, Conservatism and Humor and Politics are among the most frequently worked topics. The analysis of images, especially the cartoons, as well as the theory and methodology that involve it are also researched topics. He is the author of Politische Karikaturen und die Grenzen des Humors und der Gewalt (Budrich Verlag, 2011). 